\title{
Fatigue Characteristics and Numerical Modelling Prosthetic for Chopart Amputation
}

\author{
Saif M. Abbas and Ammar I. Kubba \\ Prosthetics and Orthotics Engineering Department, College of Engineering, Al-Nahrain University, Baghdad, Iraq \\ Correspondence should be addressed to Ammar I. Kubba; ammarkubba83@gmail.com
}

Received 24 January 2020; Revised 20 September 2020; Accepted 22 October 2020; Published 16 November 2020

Academic Editor: Parviz Ghadimi

Copyright (c) 2020 Saif M. Abbas and Ammar I. Kubba. This is an open access article distributed under the Creative Commons Attribution License, which permits unrestricted use, distribution, and reproduction in any medium, provided the original work is properly cited.

\begin{abstract}
This research is looking for three laminated composite material groups. These three groups were utilized in experimental investigation to find their mechanical properties. These properties have been used to design and manufacture a socket for a partial foot prosthesis using an ANSYS model. This socket was manufactured with a vacuum pressure device to improve its properties. The socket composite material was tested for tensile and fatigue properties; then, its results were used in the ANSYS model. The composite material matrix was laminated in an $80: 20$ ratio, and there were three types of reinforcement lamination material (Perlon, glass fiber, and carbon fiber). The mechanical property results of these tests were found as follows: using onlyPerlon reinforcement, the properties are $\sigma_{\mathrm{y}}=33.6 \mathrm{MPa}, \sigma_{\mathrm{ult}}=35.6 \mathrm{MPa}$, and modulus of elasticity $=1.03 \mathrm{GPa}$; using ( $3 \mathrm{Perlon}$ +2 carbon fiber +3 perlon) layers, the properties were $\sigma_{\mathrm{y}}=65.5 \mathrm{MPa}, \sigma_{\mathrm{ult}}=92.5 \mathrm{MPa}$, and modulus of elasticity $=1.99 \mathrm{GPa}$; and using (3Perlon +2 glass fiber +3 perlon) layers, the results were $\sigma_{\mathrm{y}}=40 \mathrm{MPa}, \sigma_{\text {ult }}=46.6 \mathrm{MPa}$, and modulus of elasticity $=1.4$ GPa. The ANSYS model used the boundary condition from the measured contact pressure between the socket and the patient's stump. The MatScan (F-socket) pressure sensor utilized these interface pressure measurements. The maximum values for the pressure were found as follows: $190 \mathrm{kPa}$ and $164 \mathrm{kPa}$, which are recorded in the posterior and lateral locations, respectively. The calculated factor of safety for the prosthesis that has been made from a selected composite material with the following layers (3 Perlon +2 carbon fiber+3 Perlon) is 1.037 which is safe for design prosthetic applications. From this study, more prosthetic designs can be modelled and manufactured using this approach. Prosthetics and orthotics are usually custom-made for each patient according to its specific requirements. So, it will be very helpful to find a procedure to analyze the prosthetics before manufacturing it.
\end{abstract}

\section{Introduction}

Partial foot amputation is a foot amputation between the ankle joint and the lower distal limb. Prostheses for partial foot amputations vary in design and function. Partial foot amputation is a type of amputation, which has many challenges for the rehabilitation physicians, the prosthesis technicians, and the patient himself in comparison to other types of amputations due to the complexity of this type of amputation. The structure of the partial foot prosthesis should be strong to protect the amputation edges from the impact at heel strike and toe off, which should also be able to control the foot deformation in dorsiflexion, plantar flexion, eversion, and inversion. Also, the prosthesis should simulate a suitable gait pattern which can allow the patient to perform normal activities. Then, the prosthesis appearance should be cosmetically acceptable. There are a wide range of partial foot amputation prostheses which can be simple as bunched up socks or foam toe fillers. They also can be a sculptured Plastazote, elastomers2, or orthoprosthesis which can have some extension that reaches to the patella tendon-bearing area [1]. As shown in Figure 1, the patient condition with a foot amputation has different names, such as transmetatarsal amputation, Chopart amputation, Lisfranc amputation, Syme's amputation, and ankle disarticulation. From these names, the amputation position through the foot can be located; some of these names are from the surgeons who deliver these amputations for the first time such as Chopart, 

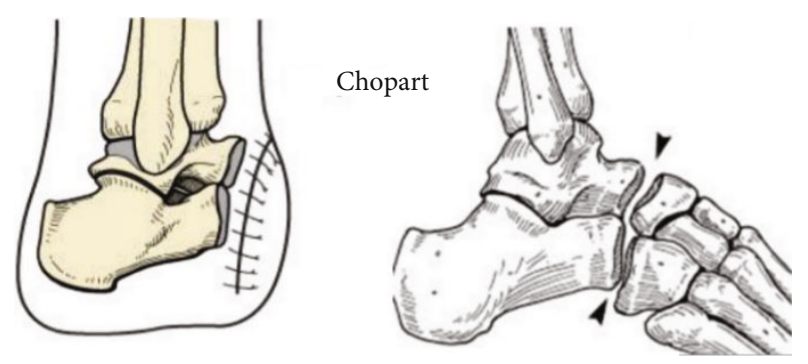

Figure 1: The Chopart amputation [7].

Lisfranc, and Syme. Partial foot amputation (PFA) is defined as losing a part from the foot, either the forefoot or the hindfoot [2], and it is typically due to diabetes [3-5]. Also, frostbite trauma and congenital anomalies can be another example for other reasons for amputation [6]. During the 19th century, François Chopart was employed at a charitable hospital in Paris, and he defined the disarticulation through the midtarsal joint [7]. At that time, this operation was thought to be having very limited applications due to the fact that the remaining of the foot is going to progress to equinovarus deformity. As time passed, more people are in favour of Chopart amputation because of its ability to keep the limbs' total length and the high percentage of success during this procedure. An improved high-topped shoe was introduced to assist patients with apropulsive ambulation due to the combination of ankle fusion and hindfoot amputation [811]. Jweeg et al. [12] used different layers of Perlon. Abbas et al. [13] worked on a composite material of carbon fiber with Perlon and Perlon only. Research to investigate KAFO made with a carbon fiber material was performed by Takhakh and Abbas [14].

Abbas investigates the effects of composite material layers on the prosthetic mechanical properties for partial foot amputation [15]. Abbas et al. investigate the mechanical properties of a prosthesis designed for partial foot amputation [16]. Takhakh et al. studied the different types of composite material lamination layers for prosthetic applications [17]. S. M. Abbas and M. H. Abbas used carbon fiber with four layers to make a composite material for an above-theknee amputation socket [18]. Salman et al. studied a composite material with a wide range of fiber reinforcements [19]. Also, Mostafa et al., Sharba et al., and Salman et al. investigate the hybrid composite material and found its mechanical properties with biaxial tensile, compression, and fatigue tests [20-22].

The aim of this work is to design and manufacture a prosthesis for Chopart amputation. This prosthesis is using one of the three composite material groups. The selected composite material is processed by simulating the prosthetic model for these three groups using the mechanical properties collected from the tests that were utilized in this study. The aim of the study was achieved by the following phases.

In the beginning, three types of lamination samples were tested in tensile and fatigue tests, and they are 3 Perlon- 2 carbon fiber-3 Perlon, 3 Perlon-2 glass fiber-3 Perlon, and 6 Perlon with a matrix of lamination $(80: 20)$ resin. Then, a study of the mechanical properties for these materials was done to

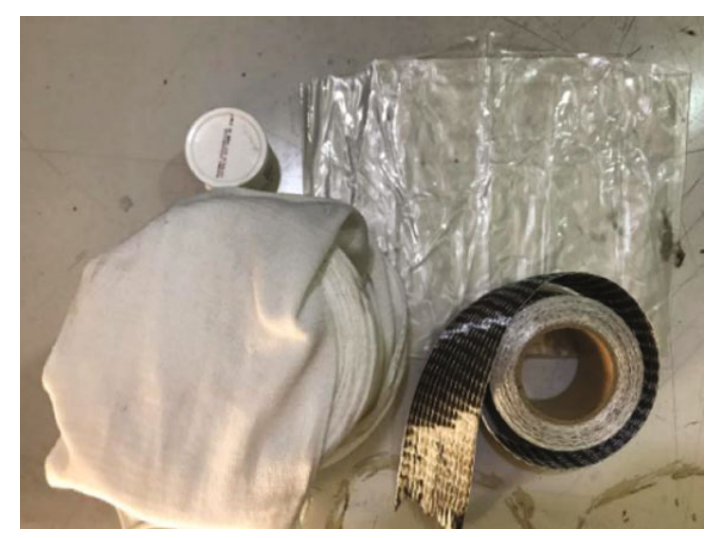

Figure 2: Prosthetic and orthotic materials.

select the best option among them to make a socket with the required performance. This study was utilized by finite element analysis using ANSYS (14.5) to determine the fatigue safety factor numerally.

The experimental and numerical data used to support the findings of this study are included within the article.

\section{Experimental Procedures}

The materials for Chopart amputation prostheses used in this study are cotton Perlon, carbon and glass fibers, and resin $(80: 20)$ with a hardener [23] as shown in Figure 2.

The tools and devices used for this research are listed as follows:

(1) A $10 * 15 * 25 \mathrm{~cm}$ mould from Jepson

(2) Pressure vacuum to prevent gaps between the fiber and the resin

(3) Tensile test machine

(4) Fatigue test for a flat specimen suitable for the composite material

Three samples were tested for each type of composite material in the tensile test device. These samples were prepared according to ASTM D638 type I [24] as shown in Figure 3(a). However, its thickness varies due to the type of lay-up.

Ten samples for each group combination were utilized for the fatigue test. The samples are shown in Figure 3(b); these samples are made according to the standard of the fatigue device while thickness of the samples varies with each group.

The following steps are measuring the partial foot amputation socket dimensions for the patient to manufacture a socket. After manufacturing, the alignment of the partial foot prosthesis was done using the alignment tools to be ready to use by the patient.

The procedure to manufacture a socket can be listed in the following steps: 


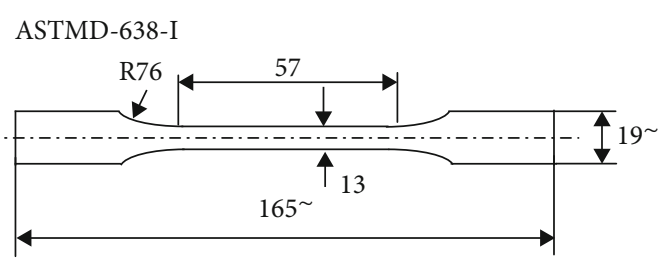

(a)

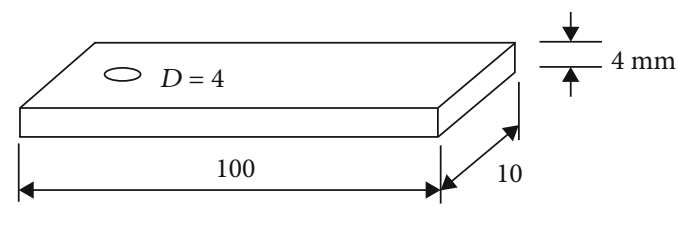

(b)

Figure 3: (a) The dimensions of the tensile specimen [24]. (b) The shape of the fatigue specimen [24].

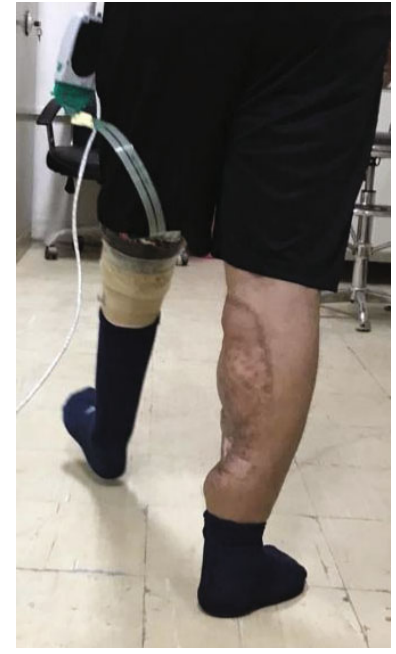

Figure 4: Patient with a MatScan sensor.

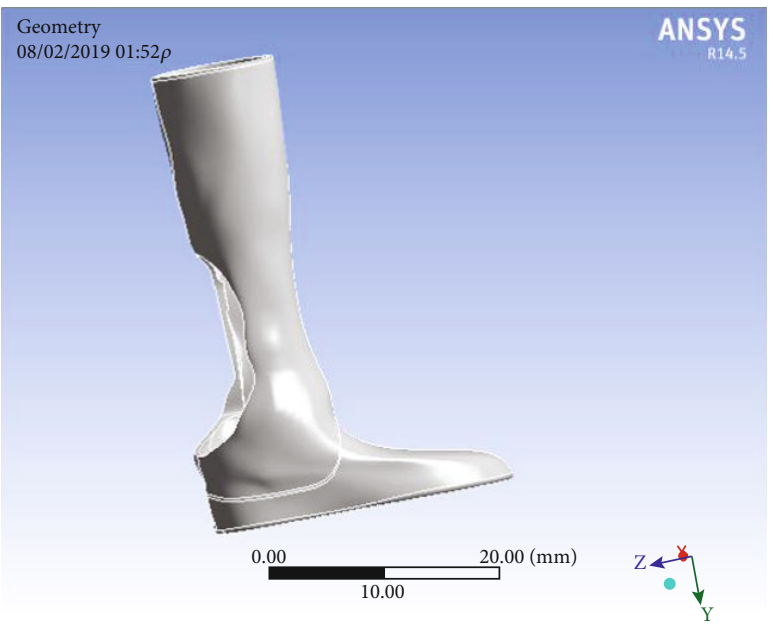

Figure 5: Prosthesis geometry model.

(1) Measuring the following parameters from the patient:

(a) The circumferences of the stump

(b) Mediolateral diameter at the calcaneus and malleolus

(c) The amputee's length

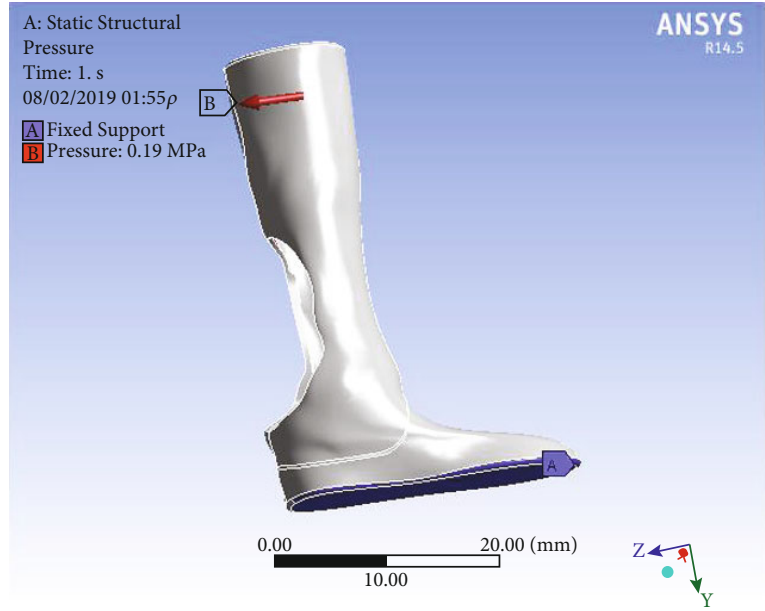

Figure 6: Prosthetic displacement condition and applied forces.

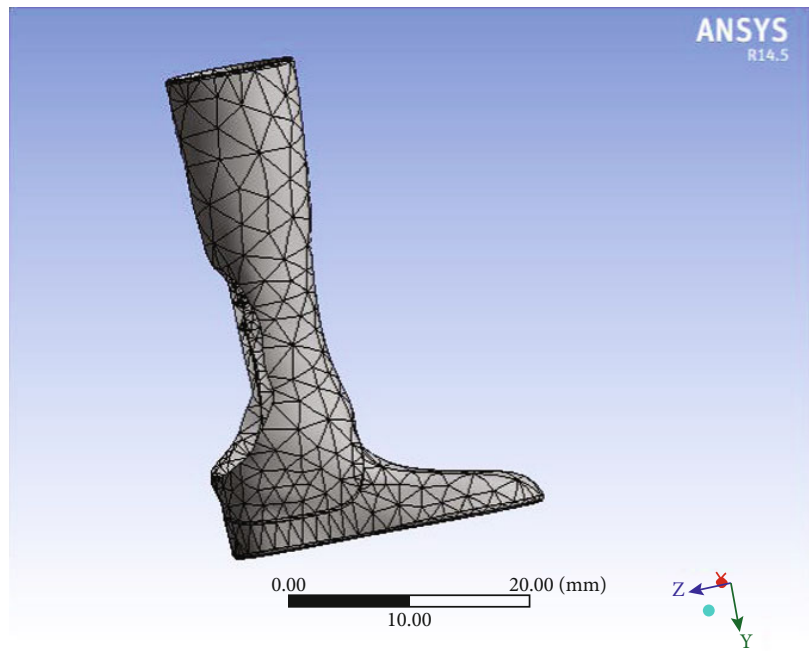

Figure 7: Prosthetic model elements.

(d) The normal foot's length

(e) The patient shoe's heel height

(2) Handing casting

(3) Preparing for rectification and cast rectification

(4) Soft socket manufacturing 
TABLE 1: The groups of lamination.

\begin{tabular}{|c|c|c|c|}
\hline No. & Layers & $\begin{array}{l}\text { Thickness } \\
(\mathrm{mm})\end{array}$ & Definition of laminations \\
\hline $\begin{array}{l}\text { Group } \\
\text { A }\end{array}$ & 8 & 3.8 & $\begin{array}{c}3 \text { Perlon-2 carbon fiber- } 3 \\
\text { Perlon }\end{array}$ \\
\hline $\begin{array}{l}\text { Group } \\
\text { B }\end{array}$ & 8 & 3.8 & 3 Perlon-2 glass fiber-3 Perlon \\
\hline $\begin{array}{l}\text { Group } \\
\text { C }\end{array}$ & 6 & 2.5 & Perlon layers \\
\hline
\end{tabular}

TABLE 2: Mechanical properties for each group.

\begin{tabular}{lccccc}
\hline Laminations & $\begin{array}{c}\text { Total no. of } \\
\text { layers }\end{array}$ & $\begin{array}{c}\text { Thickness } \\
(\mathrm{mm})\end{array}$ & $\begin{array}{c}\sigma_{\mathrm{y}} \\
(\mathrm{MPa})\end{array}$ & $\begin{array}{c}\sigma_{\mathrm{ult}} \\
(\mathrm{MPa})\end{array}$ & $\begin{array}{c}E \\
(\mathrm{GPa})\end{array}$ \\
\hline Group A & 8 & 3.8 & 65.5 & 92.5 & 1.99 \\
Group B & 8 & 3.8 & 40 & 46.6 & 1.4 \\
Group C & 6 & 2.5 & 33.6 & 35.6 & 1.03 \\
\hline
\end{tabular}

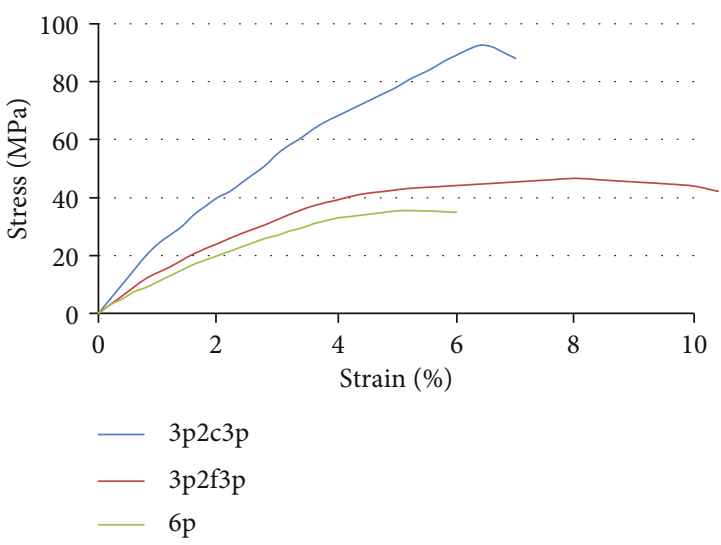

Figure 8: Tensile test curve for each group.

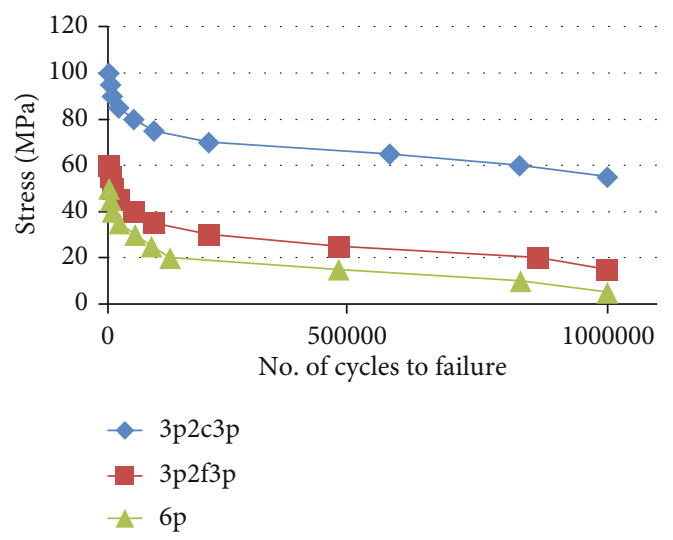

Figure 9: $S$ - $N$ curves for each lamination.

(5) Adding lamination for the socket

(6) Trimming and then finishing

Measure the interface pressure using an F-socket at different regions of the patient who wears a prosthetic type PF
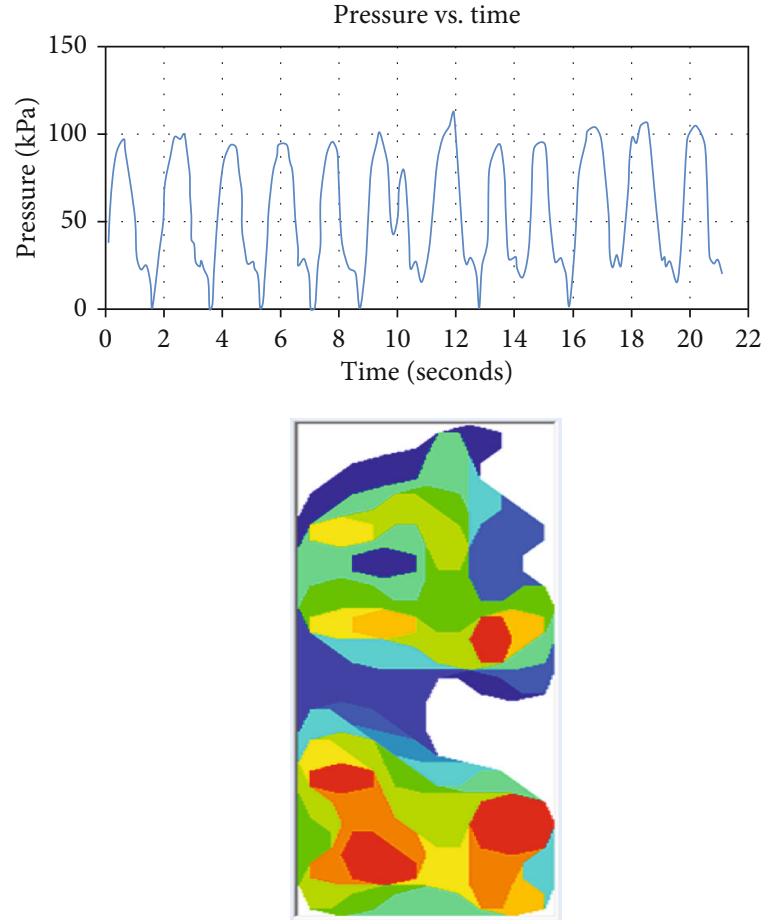

Figure 10: Pressure with time at the anterior region.
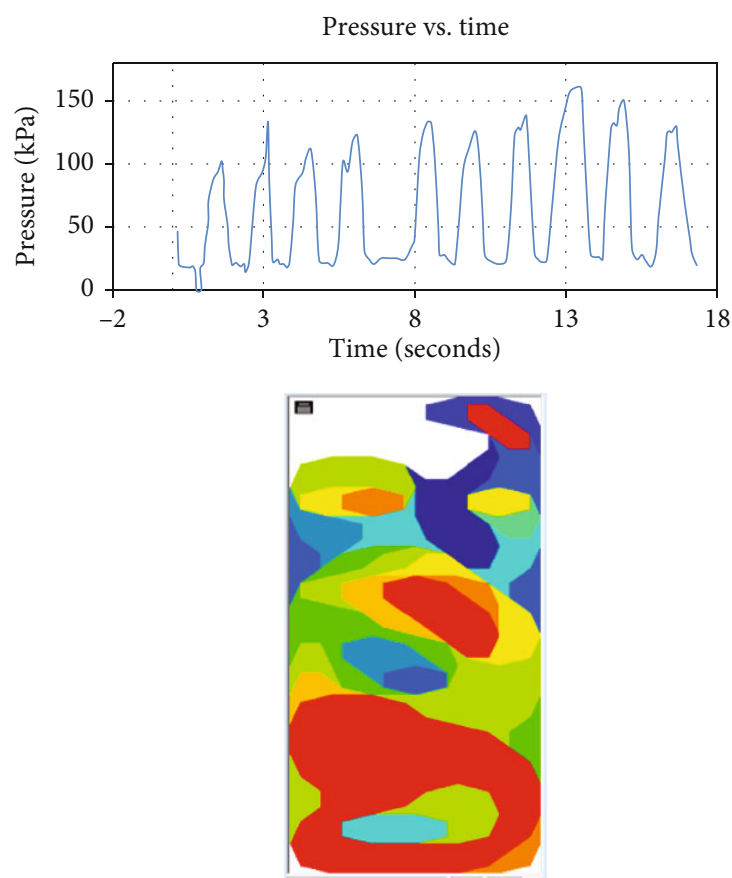

Figure 11: Pressure with time at the lateral region.

(age (55 years), height $(190 \mathrm{~cm})$, and weight $(88 \mathrm{~kg}))$. The patient suffered from left foot amputation (Chopart amputation) due to an explosion. The interface pressure was taken by using a sensor type (MatScan), shown in Figure 4, which can be used for this type of dynamic load applications. 

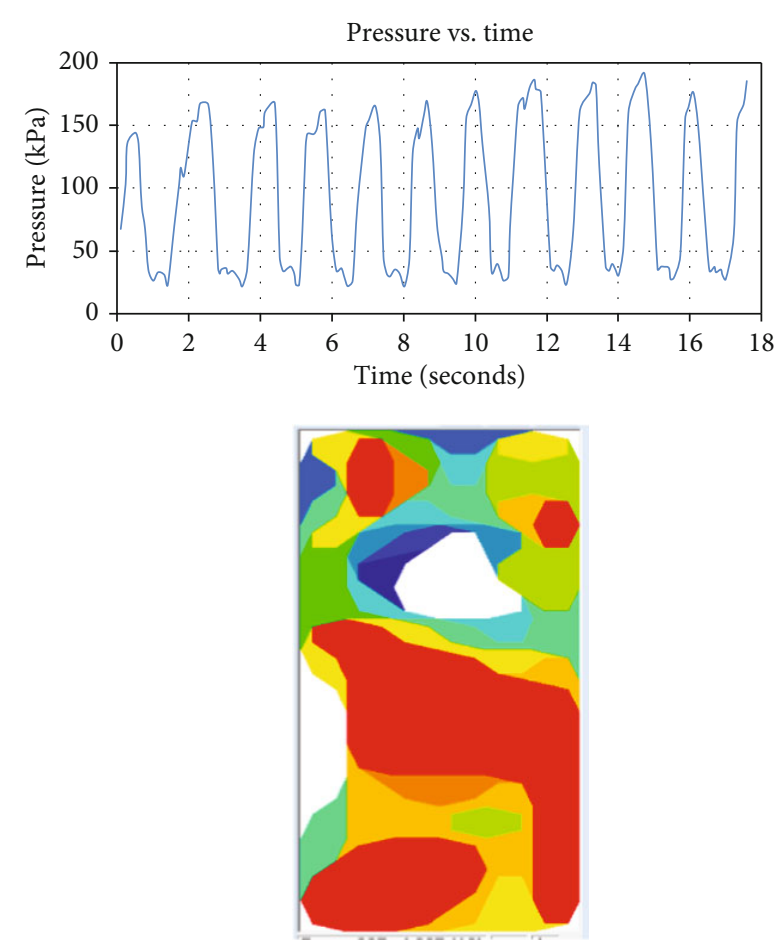

Figure 12: Pressure with time at the posterior region.
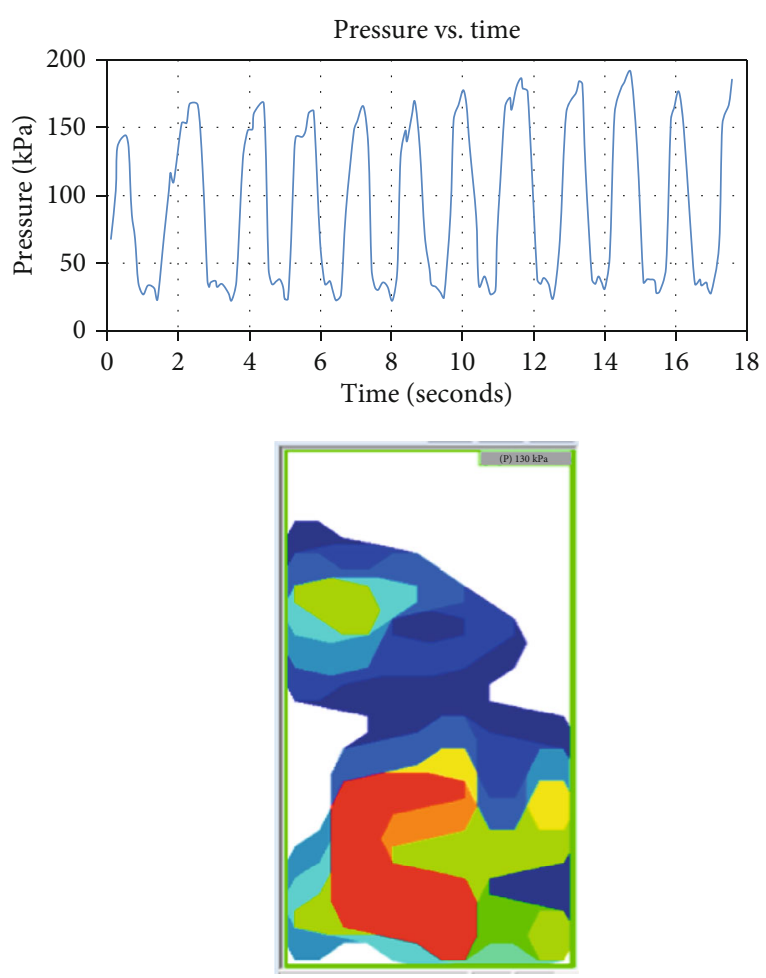

Figure 13: Pressure with time at the medial region.

\section{Numerical Analysis}

In this research, a finite element method was used to evaluate the fatigue characteristics of the prosthetic part. The prosthe- sis geometry was measured and modelled in ANSYS software as shown in Figure 5. This model used the collected mechanical properties from the tests of the three groups of the composite material, which were used to make the socket. The mechanical properties of the three different groups were used to evaluate the stresses that were generated in the prosthetics due to the weight and walking loading.

The prosthesis displacement boundary conditions and the applied forces are shown in Figure 6.

The software analyzes the prosthesis by creating elements and nodes as shown in Figure 7.

The boundary conditions for this model can be classified into displacement and applied force or pressure. The displacement boundary conditions are in the bottom of the foot where the foot is in contact with the ground. On the other hand, the force and pressure applied to the prosthetic model are from the weight of the patient $(88 \mathrm{~kg})$ and from the measured interface pressure from the MatScan sensor. The model shows how the prosthesis will respond to the applied boundary conditions above after solving this model.

\section{Results and Discussion}

4.1. Tensile Test Results. The specification of the three composite lamination layer groups is in Table 1.

The mechanical properties for these three lamination layer groups are listed in Table 2. The stress-strain curve for each lamination group is shown in Figure 8. These results were collected from the tensile test data for this study.

The found data conclude that the yield strength $\sigma_{\mathrm{y}}$ of group B has increased by $16 \%$ when two layers of glass fiber were added to the lamination in group C; also, the ultimate tensile strength $\sigma_{\text {ult }}$ has increased by about $24 \%$ and $E$ by $26 \%$. When comparing the results from groups $\mathrm{A}$ and $\mathrm{C}$, it was revealed that using two more layers of carbon fiber can increase $\sigma_{\mathrm{y}}$ by $47 \%, \sigma_{\text {ult }}$ by $62 \%$, and $E$ by $48 \%$. The increase in these mechanical properties in groups $\mathrm{A}$ and $\mathrm{B}$ is due to the mechanical properties of the glass fibers and the carbon fibers added which are higher than that of Perlon.

4.2. Fatigue Property Results. The fatigue tests were utilized for the three lamination groups in this research. The fatigue tests were done using an alternative bending testing machine with the specimen shown in Figure 3(b). The results from the fatigue testing equipment show the specimens' fracture testing stress with a total number of cycles when the fracture happened as shown in Figure 9.

Results in Figure 9 show that the amount of cycles in fatigue failure is increasing with decreasing fatigue failure stress. All the tests were conducted at room temperature. Each test was repeated three times, and the results shown in Figure 9 are the average for these data.

The collected data from the tensile and fatigue tests are used in modelling the ANSYS finite element model to compare its results.

4.3. Interface Pressure Result. The contact or interface pressure between the socket and the patient's stump was measured with a MatScan sensor as shown in Figure 4. The 
TABLE 3: Interface or contact pressure distribution between the socket and the patient's stump.

\begin{tabular}{lcccc}
\hline Socket area or regions & Anterior & Lateral & Posterior & Medial \\
\hline Interface or contact pressure $(\mathrm{kPa})$ & 108 & 164 & 190 & 130 \\
\hline
\end{tabular}

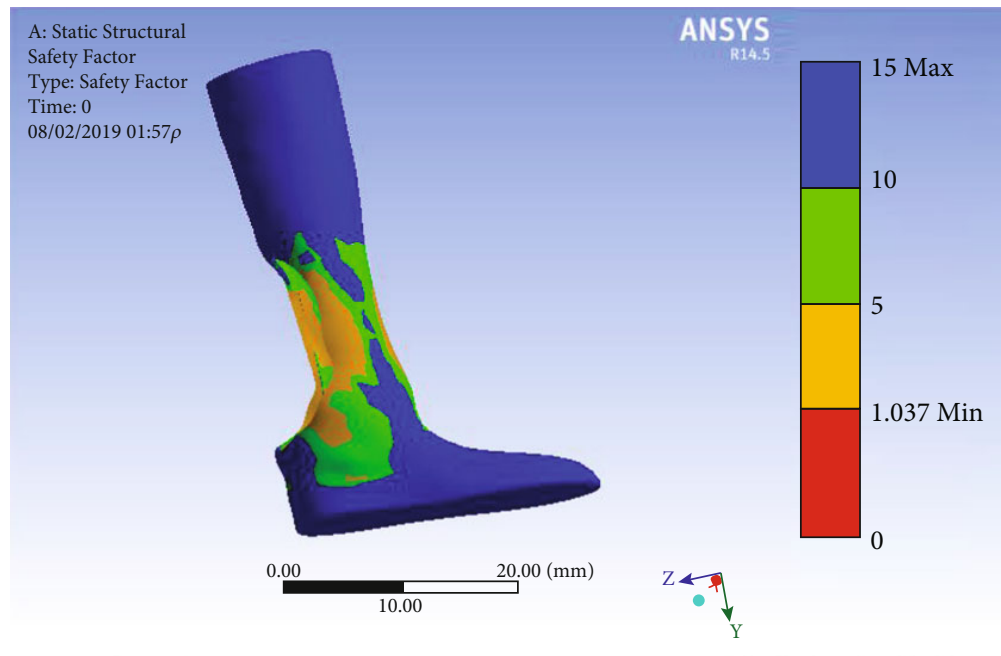

FIgURE 14: Group A fatigue factor of safety.

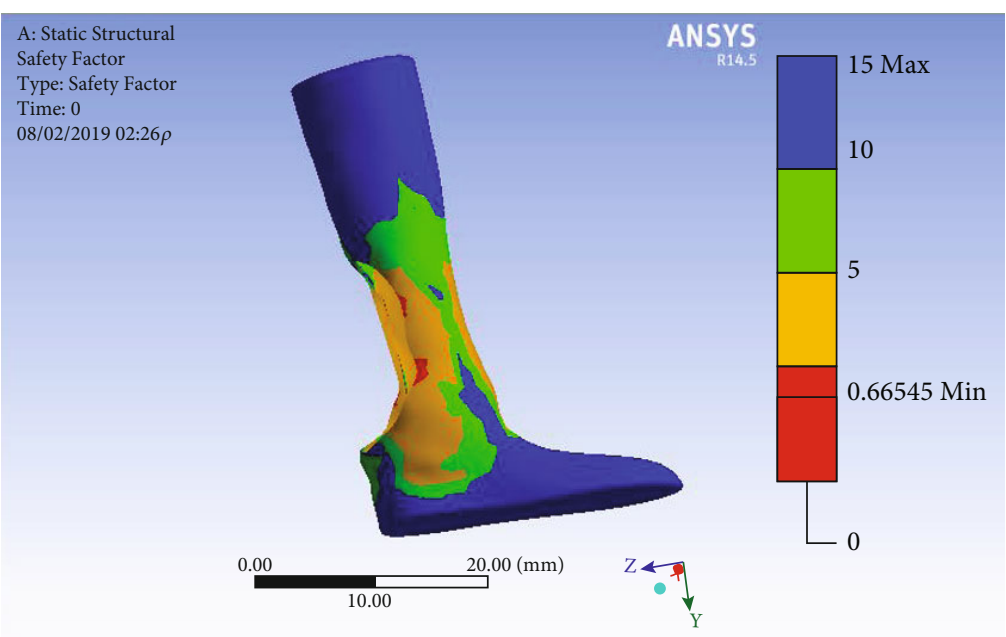

FIgURE 15: Group B fatigue factor of safety.

sensor was located on the anterior, posterior, lateral, and medial regions, and their results are shown in Figures 1013. In Table 3, the maximum pressure values of the socket and its position are listed. The higher pressure value was recorded at the posterior area with $190 \mathrm{kPa}$, and the pressure value at the lateral area is $164 \mathrm{kPa}$. This pressure distribution in the posterior and lateral muscles is due to the extra activity in these muscles during walking to avoid extra pressure in the area of tibia bone (medial region and anterior region). This type of contact pressure distribution is very common with patients having this type of amputation.

The collected data from the interface contact pressure are used as the boundary condition to solve the ANSYS finite element model.
4.4. Numerical Results. The analysis of the partial foot type Chopart prosthetic model was analyzed by finite element using computer ANSYS software, which can find the total deformation, resultant stress (von Mises stress), and fatigue safety factor.

The data show the factor of safety for the three types of the partial foot prosthetic model, which are presented in Figures 14-16, respectively. The von Mises stress results of the prosthetic three groups are shown in Figures 17-19. The total deformation is shown in Figures 20-22 which are for the three groups of the lamination composites.

The factor of safety for group A is 1.037 which is acceptable for this type of applications. 


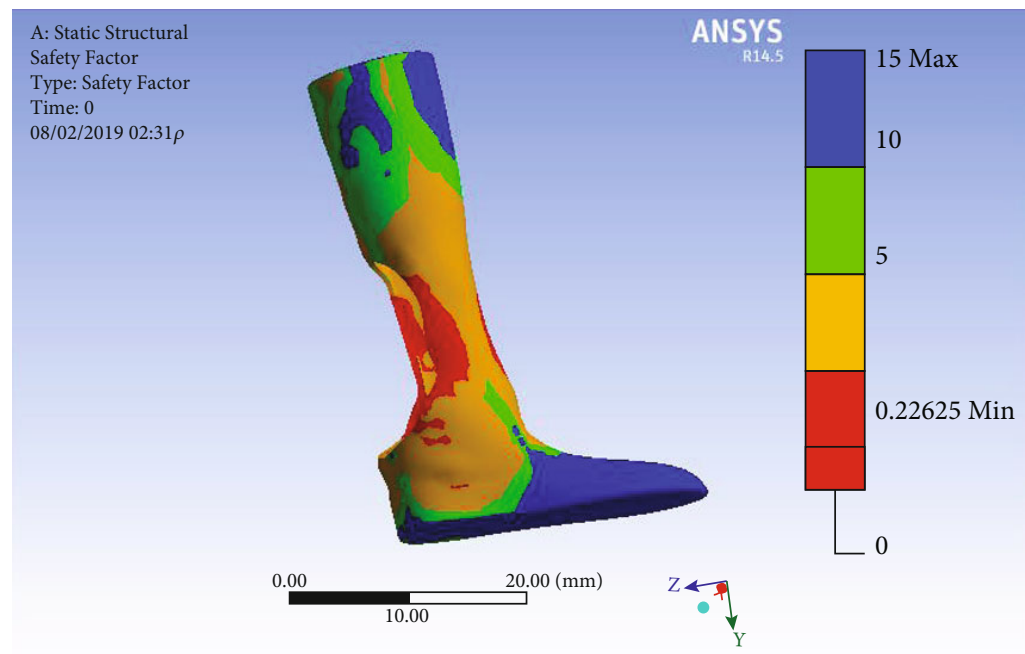

Figure 16: Group C fatigue factor of safety.

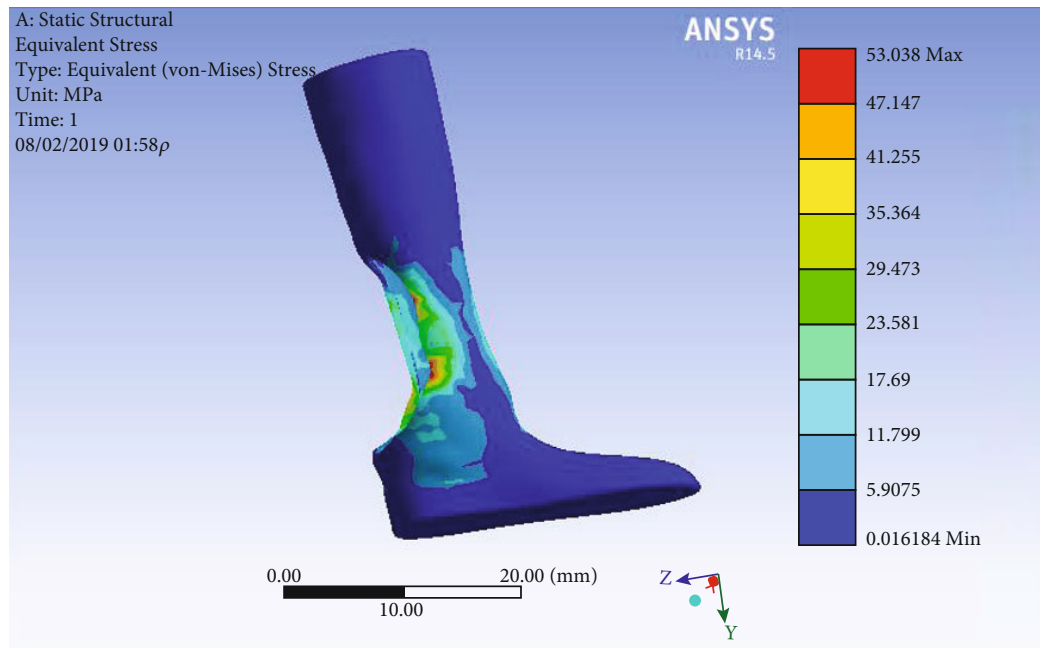

Figure 17: Equivalent stress (von Mises) in group A.

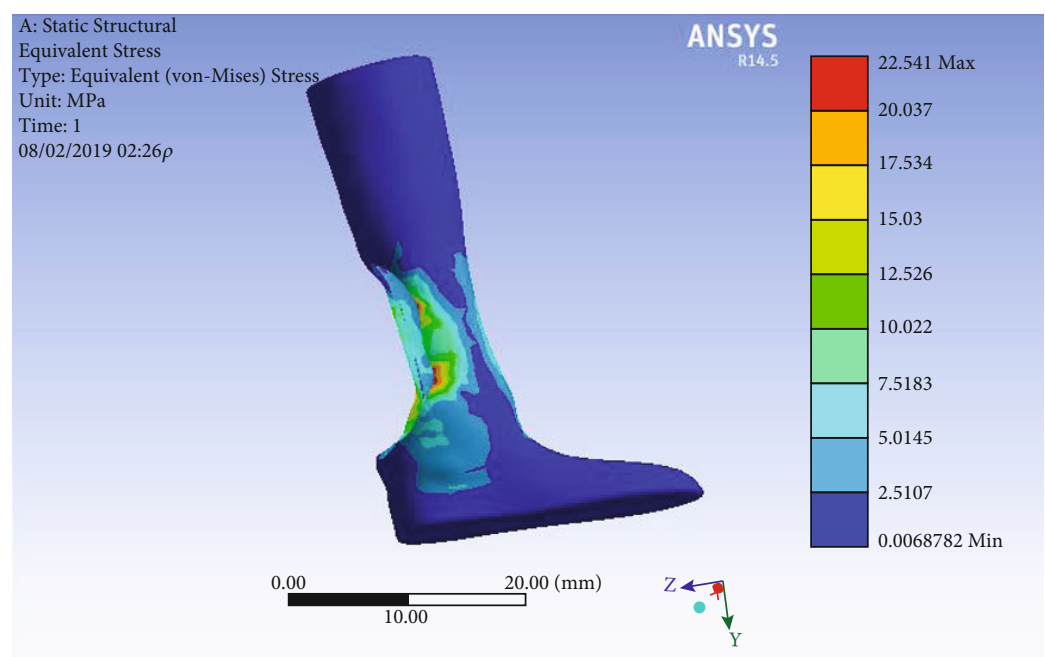

FigURE 18: Equivalent stress (von Mises) in group B. 


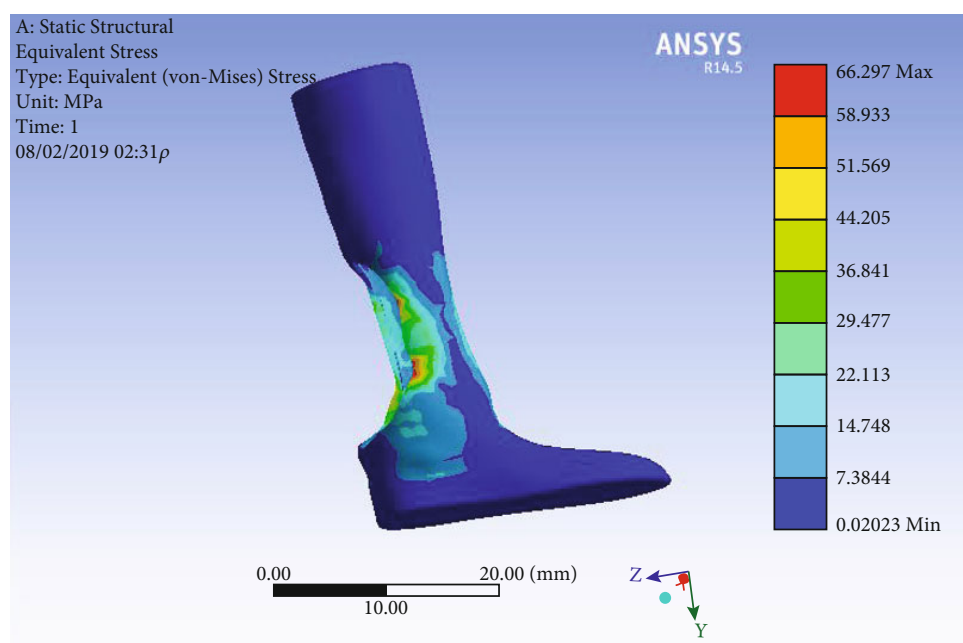

Figure 19: Equivalent stress (von Mises) in group C.

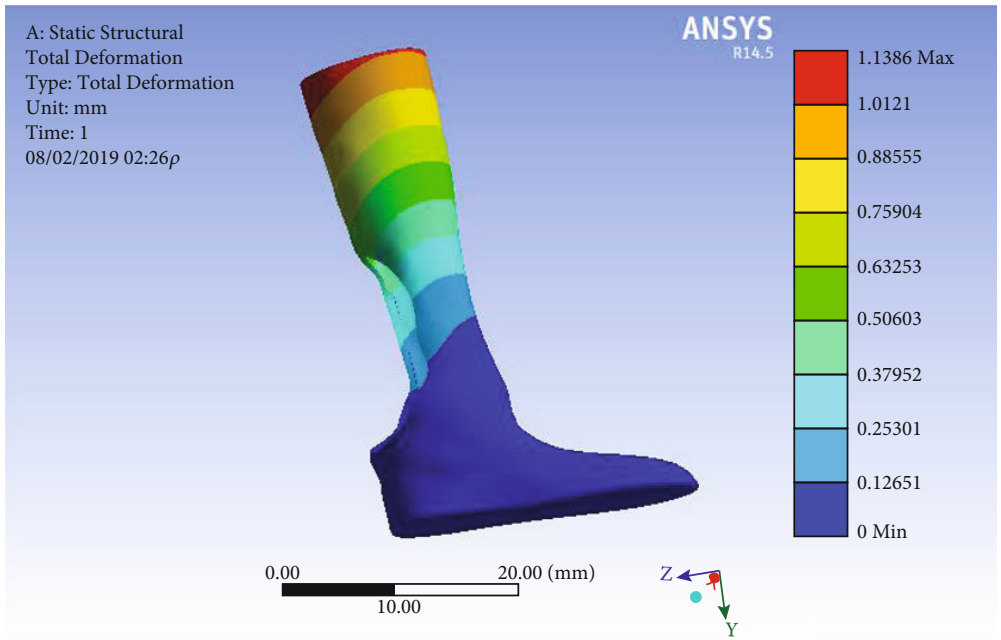

Figure 20: The total deformation in group A.

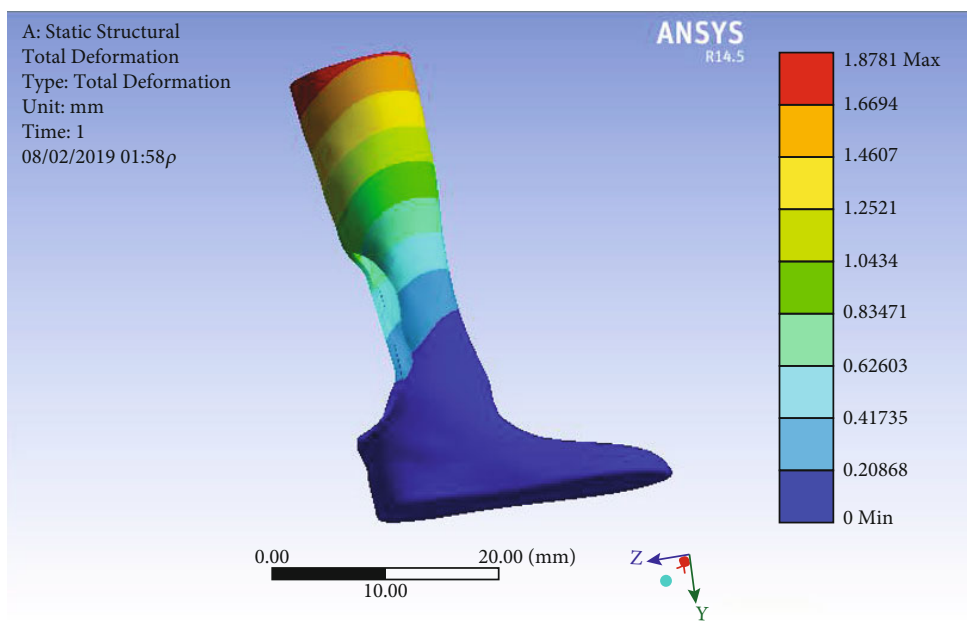

Figure 21: The total deformation in group $\mathrm{B}$. 


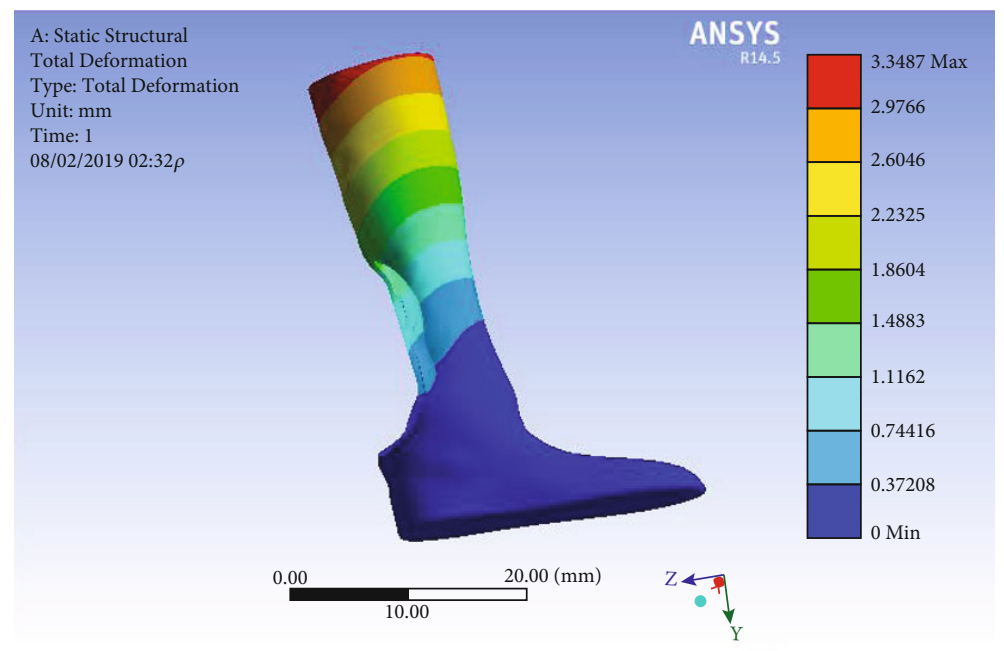

Figure 22: The total deformation in group C.

\section{Conclusions}

(1) The material selection procedure for the prosthesis used in this research can be used in a wide range of prosthetics and orthotics, as most of these applications are custom-made for each patient due to the special amputation specifications, body dimensions, patient's weight, and other factors. So, by modelling the proposed prosthesis, it can find what material is the best for the patient's requirements from the total deflection to the factor of safety from the model results

(2) There is good improvement in the mechanical properties of the laminations in groups $\mathrm{A}$ and $\mathrm{B}$ compared to group $\mathrm{C}$ due to adding two layers of glass fiber and carbon fiber, respectively. This improvement can be noticed in both the equivalent stress and the fatigue life of the prosthesis from the finite element model

(3) The maximum contact or interface pressure values measured on the prosthesis are as follows: at the lateral area, it was $164 \mathrm{kPa}$, and at the posterior area, it was $190 \mathrm{kPa}$. These maximum pressure values are due to the extra activity of the patient's muscles in this area during walking compared to the anterior regions and medial region which lead to reduced pressure on the tibia area. This contact pressure distribution should be noticed in a wide range of prostheses. Otherwise, high interface contact pressure on the tibia will make the patient uncomfortable and hurt the patient with time

(4) In this research, the selected composite material for the prosthetic model shows that the fatigue factor of safety for group A is 1.037 which can be considered safe for this type of application

\section{Data Availability}

The experimental and numerical data used to support the findings of this study are included within the article.

\section{Conflicts of Interest}

The authors declare that they have no conflicts of interest.

\section{Acknowledgments}

This research was supported by the College of Engineering, Al-Nahrain University.

\section{References}

[1] M. L. Stills, "Partial foot prostheses/orthoses," Clinical Prosthetics and Orthotics, vol. 1, pp. 14-18, 1987.

[2] C. M. Schuch and C. H. Pritham, "International Standards Organization terminology: application to prosthetics and orthotics," JPO Journal of Prosthetics and Orthotics, vol. 6, no. 1, pp. 29-33, 1994.

[3] M. J. Mueller, B. T. Allen, and D. R. Sinacore, "Incidence of skin breakdown and higher amputation after transmetatarsal amputation: implications for rehabilitation," Archives of Physical Medicine and Rehabilitation, vol. 76, no. 1, pp. 50-54, 1995.

[4] N. Miller, H. Dardik, F. Wolodiger et al., "Transmetatarsal amputation: the role of adjunctive revascularization," Journal of Vascular Surgery, vol. 13, no. 5, pp. 705-711, 1991.

[5] L. J. Sanders and G. Dunlap, "Transmetatarsal amputation. A successful approach to limb salvage," Journal of the American Podiatric Medical Association, vol. 82, no. 3, pp. 129-135, 1992.

[6] S. F. Tang, C. P. Chen, M. J. Chen, W. P. Chen, C. P. Leong, and N. K. Chu, "Transmetatarsal amputation prosthesis with carbon-fiber plate," American Journal of Physical Medicine \& Rehabilitation, vol. 83, no. 2, pp. 124-130, 2004.

[7] M. J. Mueller and D. R. Sinacore, "Rehabilitation factors following transmetatarsal amputation," Physical Therapy, vol. 74, no. 11, pp. 1027-1033, 1994.

[8] A. McDonald, "Choparts amputation," Journal of Bone and Joint Surgery British Volume (London), vol. 37, pp. 468-470, 1955. 
[9] J. R. Lieberman, R. L. Jacobs, L. Goldstock, J. Durham, and M. D. Fuchs, "Chopart amputation with percutaneous heel cord lengthening," Clinical Orthopaedics, vol. 296, pp. 86-91, 1993.

[10] B. B. Chang, D. E. Bock, R. L. Jacobs, R. C. Darling III, R. P. Leather, and D. M. Shah, "Increased limb salvage by the use of unconventional foot amputations," Journal of Vascular Surgery, vol. 19, no. 2, pp. 341-349, 1994.

[11] J. Bingham, "The surgery of partial foot amputation," in Prosthetics and Orthotic Practice, G. Murdoch, Ed., p. 141, Edward Arnold, London, 1970.

[12] M. J. Jweeg, A. M. Takhakh, and S. M. Abbas, "Characterization of materials used in manufacturing the ankle foot ortheses," International Journal of Energy and Environment Issue on Applied Mechanics Research, vol. 8, no. 4, article 291298, 2017.

[13] S. M. Abbas, A. M. Takhakh, M. A. Al-Shammari, and M. AlWaily, "Manufacturing and analysis of ankle disarticulation prosthetic socket (SYMES)," International Journal of Mechanical Engineering and Technology, vol. 9, no. 7, pp. 560-569, 2018.

[14] A. M. Takhakh and S. M. Abbas, "Manufacturing and analysis of carbon fiber knee ankle foot orthosis," International Journal of Engineering \& Technology, vol. 7, no. 4, pp. 2236-2240, 2018.

[15] S. M. Abbas, "Effects of composite material layers on the mechanical properties for partial foot prosthetic socket," $A l$ Nahrain Journal for Engineering Sciences, vol. 21, no. 2, pp. 253-258, 2018.

[16] S. M. Abbas, K. K. Resan, A. K. Muhammad, and M. Al-Waily, "Mechanical and fatigue behaviors of prosthetic for partial foot amputation with various composite material types effect," International Journal of Mechanical Engineering and Technology (IJMET), vol. 9, no. 9, pp. 383-394, 2018.

[17] A. M. Takhakh, S. M. Abbas, and A. K. Ahmed, "A study of the mechanical properties and gait cycle parameter for a belowknee prosthetic socket," IOP Conference Series: Materials Science and Engineering, vol. 433, article 012045, 2018.

[18] S. M. Abbas and M. H. Abbas, "Analysis and manufacturing of above knee prosthesis socket by using revo fit solution," IOP Conference Series: Materials Science and Engineering, vol. 454, article 012025, 2018.

[19] S. D. Salman, Z. Leman, M. T. H. Sultan, M. R. Ishak, and F. Cardona, "Kenaf/synthetic and Kevlar ${ }^{\circledR / c e l l u l o s i c ~ f i b e r-~}$ reinforced hybrid composites: a review," BioResources, vol. 10, no. $4,2015$.

[20] N. H. Mostafa, Z. N. Ismarrubie, S. M. Sapuan, and M. T. H. Sultan, "Effect of fabric biaxial prestress on the fatigue of woven E-glass/polyester composites," Materials \& Design, vol. 92, pp. 579-589, 2016.

[21] M. J. Sharba, Z. Leman, M. T. H. Sultan, M. R. Ishak, and M. A. A. Hanim, "Tensile and compressive properties of woven Kenaf/glass sandwich hybrid composites," International Journal of Polymer Science, vol. 2016, Article ID 1235048, 6 pages, 2016.

[22] S. D. Salman, Z. Leman, M. T. Sultan, M. R. Ishak, and F. Cardona, "The effects of orientation on the mechanical and morphological properties of woven Kenaf-reinforced poly vinyl butyral film," BioResources, vol. 11, no. 1, 2015.
[23] Otto Bock Material and Systems, "Otto Bock Catalog. Otto Bock,” 2007, https://www.ottobock.es/media/cat\%C3\% Allogo-de-materiales-gb.pdf.

[24] Standard Test Method for Tensile Properties of Plastics, "American society for testing and materials information, Handing series," 2000, http://www.dept.aoe.vt.edu/ aborgolt/aoe3054/manual/expt5/D638.38935.pdf. 